\title{
Educator and institutional entrepreneur: Cooperative Extension and the building of localized food systems
}

\author{
Rebecca Dunning, ${ }^{a} *$ Nancy Creamer, ${ }^{\mathrm{b}}$ Joanna Massey Lelekacs, ${ }^{\mathrm{b}}$ John O'Sullivan, ${ }^{\mathrm{c}}$ \\ Tes Thraves, ${ }^{\mathrm{b}}$ Teisha Wymore ${ }^{\mathrm{b}}$ \\ Center for Environmental Farming Systems
}

Submitted 14 July 2012 / Revised 24 September 2012 / Accepted 24 September 2012 / Published online 6 November 2012

Citation: Dunning, R., Creamer, N., Massey Lelekacs, J., O’Sullivan, J., Thraves, T., \& Wymore, T. (2012). Educator and institutional entrepreneur: Cooperative Extension and the building of localized food systems. Journal of Agriculture, Food Systems, and Community Development, 3(1), 99-112. http://dx.doi.org/10.5304/jafscd.2012.031.010

Copyright (C) 2012 by New Leaf Associates, Inc.

\begin{abstract}
Cooperative Extension Service educators work within an established network of offices throughout the United States and have the potential to tap both structural and relationship networks to foster collaboration and catalyze institutional change in food systems. The
\end{abstract}

All authors are associated with the Center for Environmental Farming Systems, a joint partnership between North Carolina State University, North Carolina Agriculture and Technical State University, and the North Carolina Department of Agriculture and Consumer Services.

${ }^{a}$ Corresponding author: Rebecca Dunning, Center for Environmental Farming Systems; 226 Kilgore Hall, Box 7609; Raleigh, North Carolina 27695 USA; rebecca.dunning9@gmail.com

b Center for Environmental Farming Systems, Department of Horticultural Science, North Carolina State University.

${ }^{\mathrm{c}}$ Center for Environmental Farming Systems, North Carolina Agricultural and Technical State University Cooperative Extension Service. prerequisites and processes to generate systemic change, however, challenge the established logic of information transfer that has dominated Extension Service practice. This paper considers the nature of Extension's engagement in food systems both conceptually and in practice, based on a two-year train-the-trainer professional development project in North Carolina designed to support the emergence of local food systems. Extension initiatives are examined in light of two social change models: diffusion of innovations, based on knowledge transfer and spatial diffusion; and institutional change, based on inter-organizational relationships and mutually held cultural understandings. We suggest that the work of food systems change is more usefully viewed through an institutional lens, with extension educators serving as "institutional entrepreneurs" to address and leverage the concerns of the communities in which they are embedded into lasting food system change. 


\section{Keywords}

community engagement, community food systems, cooperative extension service, diffusion, institutional change, institutional entrepreneur, interviews, local food systems, networks, North Carolina

\section{Introduction}

One measure of American agricultural success over the prior 100 years, rapid increases in yields per acre, is largely attributed to the unique partnership and networked linkages that exist between landgrant research institutions, farmers, and agricultural extension agents and specialists in the Cooperative Extension Service (CES) (Huffman \& Evenson, 2006). Ideally, CES agricultural educators act as a conduit along which information flows among these entities, with educators assessing needs through their close interaction with farmers and relaying feedback to land-grant university researchers, and researchers responding through basic and applied research. Behavioral change among target populations is assumed to occur via knowledge transfer, with innovations passed on to agricultural adopters via educational programs, and information spreading through networks composed of university-based extension specialists, extension field agents, and farmer-adopters. The CES thus operates on a model of innovation diffusion (Rogers, 1983, 2005), whereby information is channeled to initial adopters through educational programming and is then disseminated to others in the same geographical area (Boone, Safrit, \& Jones, 2002; Seevers, Graham, \& Conklin, 2007). A visual analogy sometimes invoked is that of "an oil drop on water," with information spreading rapidly across relationship networks from the initial introduction via extension programming.

This article discusses the challenges to the diffusion logic of behavioral change posed by the burgeoning local food systems (LFS) movement, and the opportunities the movement presents for the CES to respond to community calls to alter the way in which food is produced and distributed. LFS components are not easily conceived of as separable innovations to be packaged and delivered in distinct educational programs to end users. Both the nature of the innovation and the potential set of adopters are very different than that imagined by the diffusion logic of knowledge transfer. We begin this paper with a discussion of LFS as a new arena of extension practice and programming. We then discuss two models of behavioral change: the diffusion model that has guided extension practice, and a model of systemic change grounded in institutional theory. We then use the findings from a 2009-2011 U.S. Department of Agriculture (USDA) Southern Sustainable Agriculture, Research and Extension Professional Development Program project in North Carolina to illustrate the institutional approach and the powerful potential role that CES educators can play in creating more localized food systems. The paper concludes with suggestions to enhance Cooperative Extension capabilities to maximum effect for food system change.

\section{Building Local Food Systems}

The local foods movement continues to grow in both the popular imagination, from Omnivore's Dilemma to parodies in the TV series Portlandia, and in policies with potentially significant consequences (e.g., USDA's rhetorical and funding support for the development of food hubs ${ }^{1}$ ). "Local foods" functions as a flexible rhetorical and organizational term under which various constituencies can operate and collaborate, with advocacy positions as diverse as sustainable farming, food justice, economic development, and children's health. Although there are dangers in putting too much faith in "local" to solve all food-related problems (Born \& Purcell, 2006), the term has provided an entry point for more broad-based discussions of food systems and their multiple dimensions.

Meeting just two of the objectives of localizing a food system - increasing the supply of and increasing the demand for locally produced foods - requires long-term changes to make food available, accessible, and utilized over nonlocal choices. Advocates must address multiple interconnected elements, filling in gaps in processing and distribution, encouraging shopping and eating patterns to match local seasonality, and extending off-season production. Grocery stores accustomed to national

${ }^{1}$ See http://www.ams.usda.gov/AMSv1.0/foodhubs 
and global distribution channels and meat producers tied into multiple-year contracts are bound by structural position (i.e., the relative location and pattern of contact among entities) and personal relationship ties that take time and concerted effort to alter. Transforming structures, relationships, and mindsets is more than a matter of making the multiple benefits of local food systems known or providing subsidies to increase the volume of seasonal foods in groceries or corner markets. The transformation is a long-term endeavor that requires coordinated efforts among multiple partners and an understanding of how change in one part of the food system creates change in another.

As such, reshaping food production, consumption, and waste re-use requires a systems approach to problem solving (Koc \& Dahlberg, 1999; Meter, 2006, 2010). This approach assumes that viable solutions arise by addressing concerns within the context of the overall system, with equal attention given to the interlinked system elements (e.g., farms, wholesalers, grocers, consumers) and the interactions among these elements. Systems approaches also consider the influence of the social, economic, and regulatory and political context in which the system is embedded. Similar elements or types of relationships may function well in some contexts, and fail in others. A produce aggregation co-op may operate spectacularly in one city or county, operating smoothly to link producers and buyers, and fail just as spectacularly in another location.

Accomplishing localization of production and supply entails paying adequate attention to the elements (e.g., facilities to aggregate local product for consumers), the relationships between these elements (e.g., personal relationships between grower and consumer, legal relationships such as contracts) and context (e.g., consumers' preferences for local foods). Attention to relationships means fostering ongoing mechanisms of communication and collaboration across entities to generate feedback and create self-sustaining systems that extend beyond single projects (Feenstra, 2002; Sundkvist, Milestad, \& Jansson, 2005).

An effective means to challenge and alter established practices is the use of an "institutional entrepreneur," an individual or organizational entity that holds legitimacy among stakeholders and has widely networked connections that can be used to leverage resources to create new practices or transform existing ones (DiMaggio, 1988; Fligstein, 1997; Maguire, 2007; Rao, Morrill, \& Zald, 2000). As suggested in the following sections of this paper, state Cooperative Extension Services have the capacity to be major drivers of food system change. CES educators are embedded in local communities and can forge links among the entities that, in collaboration, can build localized food systems. For example, agents could connect school nutritionists who may be unaware of local produce seasonality, PTAs looking for healthier cafeteria options, producers holding required food safety certifications, and procurement officers in the school system. Encouraging food system transformation through extension institutional entrepreneurship is somewhat restrained, however, by the innovation-diffusion logic that continues to dominate extension practice. Below we discuss the innovation-diffusion perspective on change and compare it to one grounded in institutional theory.

\section{The Logic of Diffusion and Extension Practice}

The diffusion of innovation model refers to the spread of practices, technical information, and abstract ideas and concepts within a social system, with the information flowing from sources to adopters via channels of communication and influence (Rogers, 1983). The source or adopter may be any social actor, including an individual, group, organization, community, state, or nation. Diffusion as a model of social change derives from the work of rural sociologists Ryan and Gross (1943), who analyzed the spread in planting of hybrid corn across Iowa producers in the 1930s. Rogers $(1983,2005)$ elaborated upon and systematized the model of diffusion, identifying the characteristics of an innovation and of a targeted adopting audience that are associated with more rapid and widespread diffusion. The diffusion model works well, and can be evaluated as working well, when innovations have particular characteristics: an observable relative advantage over existing practices; high compatibility with existing practices; a low level of complexity; a high degree of observability so that others may see 
the innovation in use; and a high degree of trialability that allows the potential user to try the innovation before full adoption (Bohlen, 1961; Rogers, 2005). The diffusion paradigm itself has been studied as a case of diffusion, with use of the model spreading across the social sciences in the years since Ryan and Gross's publication (Valente \& Rogers, 1995). Diffusion processes continue to be used to explain the adoption of practices, from welfare policy adoption across the American states (Arsneault, 2000) to ordination of women across religious organizations (Chaves, 1996).

The organizational structure of the CES aligns with the innovation-diffusion model of social and behavioral change. With offices embedded in local communities, extension educators provide the relational channels along which innovative practices, technologies, and information flow. Innovations are delivered via educational programs in the form of trainings, classes, and demonstration workshops. The evaluation of extension programming effectiveness, which has come under greater scrutiny as government budgets tighten, is based largely on measures of knowledge transfer. The degree of transfer is measured by the increase in self-perceived or actual knowledge gained during a training, as ascertained by pre- and post-training surveys, and by estimates of the degree to which the innovation was adopted by producers and led to actual production increases (Boone et al., 2002; Seevers et al., 2007).

By virtue of being a complex set of practices and beliefs, LFS are not easily transferred to potential adopters as innovations. Rather than a single practice or even set of practices, LFS are conglomerations of multiple elements and relationships embedded in complex contexts, with multiple end goals that may not be easily quantified. How do we "transfer" LFS through extension channels and using conventional training practices to an audience of potential adopters? How can we evaluate that a local food system has been successfully "changed," and thus make conclusions about extension efficacy? Although select elements of building LFS can be packaged and delivered effectively via training programs - for example, the methodology of Rapid Market Assessments (Lev, Brewer, \& Stephenson, 2008) - it is difficult to imagine a set of training packages and innovationdiffusion delivery methods that could create holistic system change adapted to individual contexts.

\section{Local Food Systems and Institutional Change}

An "institution" refers to beliefs, behaviors, and the formal and informal rules that emerge to perpetuate these beliefs and behaviors over time (North, 1991). An institutional perspective assumes that changes in beliefs and behaviors occur slowly over time within social, economic, and political contexts and webs of relationships that exist between social actors (e.g., individuals, organizations). Rules include formal laws, such as zoning regulations, as well as informal conventions and norms of behavior, such as consuming food while walking or driving. Institutional change is tracked through time by measuring change in beliefs and behaviors. The direction and speed of change depends crucially on the existence and nature of the ties between social actors and the commonality among cultural frames of reference. Relationships and frames of reference are often self-reinforcing. For example, a sustainable farmer can find common ground with a nutritionist on the importance of advocating for fresh local produce to be served in elementary schools, these common views strengthen the relationship ties yielding increased interaction, and this interaction further bolsters the actors' beliefs in the value of local foods.

Diffusion and institutional models of change are similar in that both assume that relational channels among actors speed the rate of adoption to the degree that the new practices (patterned behaviors) and beliefs are "rendered salient, familiar, and compelling" to potential adopters (Strang \& Soule, 1998, p. 276). Institutional models of change, however, assume a greater degree of embeddedness of beliefs and behaviors in social contexts. The context includes both the relational structures - the network ties linking individuals and organizations - and cultural understandings that create consensus around the types of actions that "make sense."

Theorizing that institutions are fields of social life can help us visualize this contextual and spatial dimension, creating an image that links behaviors, 
beliefs, and resulting rules and practices into a defined institutional field. An institutional field is composed of a set of institutions and a network of organizations and relationships that perpetuate the institutional beliefs, behaviors, and rules (DiMaggio \& Powell, 1983; Tolbert \& Zucker, 1983). Food system institutional fields are the combinations of practices, cultural understandings, and formal and informal rules related to the production and distribution of food that are embedded in a network of individual and organizational relationships. Dominant ideas and practices are reproduced through time via these ongoing relationships, but can be challenged by the formation of new relationship networks and the entrance of new beliefs and practices (Barley \& Tolbert, 1997; Sewell, 1992). Institutionalized relationships and practices are resistant to change because they have been engrained in habit and tradition. Change in the field results when new relational connections are forged, these interactions become integrated into structures that define patterns of coalitions, and actors in the emerging institutional field develop a mutual awareness of being involved in a common enterprise (DiMaggio \& Powell, 1983; Colyvas \& Powell, 2006).

LFS can be characterized as an institutional field still under development, with normative beliefs, concrete practices, organizations, and networks of relationships not yet solidified. Local food system components and relationships might emerge through transformation of the existing dominant, conventional means of producing and consuming food. Or, the emerging system may proceed on a parallel track, with an alternative system arising alongside the conventional one. Most likely is the emergence of some combination of these two models, dependent on local and regional contexts and on the particular configuration of social actors engaged in the localization process.

To what extent individual communities are able to institutionalize practices that localize food systems - such as school menus designed around local seasonality, land use rules that encourage the use of vacant municipal lands for community gardening, or representation by small sustainable farmers on local government advisory boards depends in large part on the degree to which change agents are able to connect with like-minded actors and institutionalize these connections into ongoing collaborations. An effective way to enact institutional change is to link advocacy projects (e.g., increasing demand for sustainably grown produce from local small and medium-sized farmers) to pre-existing organizational routines (e.g., sourcing routines as currently used by broadline wholesalers, or procurement policies of public institutions such as schools) (Barley \& Tolbert, 1997; Ramasawmy \& Fort, 2011).

Change that occurred in the institutional field of solid waste disposal provides an instructive analogy for the current localization of food systems. The environmental movement of the late 1960s and 1970s put solid waste recycling on the debate agenda as a possible means to deal with waste, and was driven by grassroots nonprofit buyback centers (Lounsbury, Ventresca, \& Hirsch, 2002), much in the same way that early organic cooperatives constituted some of the original local food networks. Heightened social anxiety in the 1980s regarding landfill space and opposition to locating new incinerators and landfills near communities propelled the emergence of recycling as a reasonable, legitimate solution to what had become a widely recognized social problem, and spurred the emergence of the modern recycling industry (Lounsbury et al., 2002). This parallels current anxieties concerning food health and safety, particularly related to growing adult and childhood obesity rates and diet-related diseases.

Recycling as a new institutional field included a set of distinct practices and innovations, but these could not simply be transferred via educational programming to public works departments. Changes in waste disposal required collaboration and coordination among networks of individuals and organizations, changes in individual consumer behavior (cleaning and sorting of containers), and creation of a chain of new organizations and businesses to handle waste. Early adoption of recycling practices in communities depended on change agents who mobilized government officials to support the use of public resources, residents to incorporate recycling as a part of everyday life, and businesses to use waste products as a production input. In much the same way, the nature of and 
speed with which elements of LFS are adopted depends upon change agents' ability to harness community resources, identify opportunities, and connect with stakeholders. As discussed in the following section, Cooperative Extension educators are positioned to act as these local change agents or "institutional entrepreneurs."

\section{Extension Educators as Institutional Entrepreneurs}

Institutional entrepreneurship refers to the activities of social actors "who leverage resources to create new institutions or transform existing ones" (Maguire, Hardy, \& Lawrence, 2004, p. 667; see also Dimaggio, 1988; Dorado, 2005, Lawrence \& Phillips, 2004). Extension educators' ability to act as institutional entrepreneurs hinges on the degree to which they harness resources and opportunities that exist in the relational communities in which they are embedded, catalyze collaboration across actor networks, and thus spur action that otherwise would not have occurred. Extension educators are in prime structural and relational positions to convene a diverse array of partners who can collaborate on LFS initiatives. The initiatives can be decided upon communally by stakeholders convened by the extension educator to discuss community issues (Raison, 2010; Thomson, Radhakrishna, \& Bagdonis, 2011). The instigation of collaboration prompts change in the institutional field.

Extension educators are trained to ascertain community needs and respond to these needs through educational programming (Safrit, 2011; see also Boone, et al., 2002). Educators investigate community needs through forums, focus groups, surveys, personal contacts, and formalized advisory boards. Needs are considered through the lens of the four Extension Service program areas (Agriculture and Natural Resources, Family and Consumer Sciences, 4-H Youth Development, and Community Development), around which educational programs are designed for targeted audiences. This cycle of assessment, educational program development, and then delivery to identified audience is a process crafted from "diffusion of innovations" thinking, but is arguably less suited to the collaborative approach needed for food systems transformation.
In the following section of this paper we describe a grant-based program used in North Carolina in 2009-2011 as a means to facilitate food systems transformation. The program sought to work within the organizational framework of Extension, taking advantage of its structural and relationship features, but empowered agents to take on more active roles as institutional entrepreneurs in their communities. The study provides an example of bridging the two models of behavioral change to transform food systems, and offers evidence of the types of outcomes that can result.

\section{Institutional Entrepreneurship in North Carolina}

Between 2009 and 2011, the North Carolina Cooperative Extension Service (NCCES) and the Center for Environmental Farming Systems (CEFS), a joint partnership between North Carolina State University, North Carolina Agriculture and Technical State University, and the North Carolina Department of Agriculture and Consumer Services, led a "train-the-trainer" project intended to catalyze the spread of local food systems knowledge and activities across the state. In year one of the two-year project, six county-based teams led by Extension agents and including community members were trained in the conceptual framework of community-based food systems and project development and realization. Subsequently, each of the six teams chose a second county-based team to mentor over year two of the grant. ${ }^{2}$

The North Carolina training project was funded by the USDA's Southern Region Sustainable Agriculture Research and Education (SARE) program. SARE has emerged as a major source of funding for efforts to support sustainable agricultural practices and, more recently, local food system development. ${ }^{3}$ SARE provides funds for

\footnotetext{
${ }^{2}$ The final report and training materials generated for the project, Training the Trainers in Community Based Food Systems: A Project-Oriented Case Study Approach, can be accessed at http://go.ncsu.edu/sarepdpcbfs

${ }^{3}$ Between its founding in 1988 and 2008, SARE provided funding for over 3,700 projects and its annual budget grew to USD19 million. In April 2012, the Senate Appropriations Committee approved an increase of 18 percent in annual funding and gave support to a Sustainable Agriculture Federal-
} 
research and community sustainable development projects and, through its Professional Development Program initiative, funds training programs for agricultural professionals and educators (SARE, 2012). Since 1988, SARE has awarded a total of USD27.4 million for 430 Professional Development Program (PDP) grants.

The North Carolina PDP project was designed to build on the structural and relational capabilities of the Extension Service in the state. NCCES agents in Agriculture \& Natural Resources, Family $\&$ Consumer Sciences, and 4-H Youth Development had been engaged in a host of local foods activities, ranging from farmers' markets and community and school gardens to farm tours and county and municipal food policy councils. The number and variety of activities across counties in North Carolina varied widely, however, with a few counties having numerous local foods projects and others having few to none. CEFS and the NCCES envisioned the PDP project as a means to jumpstart food system transformation in counties where agents had not been engaged in local food systems work, or had been working on LFS but without the active engagement of community partners. Thus, the PDP utilized the Extension diffusion-ofinnovations structure to reach agents and community members, with trainers transmitting information to these individuals who would then disseminate information on local food system benefits in their home counties. As part of the project, however, county Extension leaders were directed to convene teams of community members who would collaborate in defining and bringing to fruition a LFS initiative that made sense in their own communities. In this way, the PDP empowered Extension educators to act as institutional entrepreneurs.

Throughout the two-year period, CEFS provided informational resources, organizational support, and seed funding to each team. Informational resources took the form of an initial two-day training for year one partners in the first months of the project and a resource notebook and resource website for all teams; participatory workshops on

State Matching Grant Program as a new component of SARE (National Sustainable Agriculture Coalition, 2012a, 2012b). goal-setting and community engagement (in-person site visits with CEFS staff and a communityengagement contractor, and a webinar held on these topics); and support for some Extension partners to attend the Southern Sustainable Agriculture Working Group conference midway through the project. Scheduled conference calls during the two years facilitated the sharing of experiences and feedback among all teams. Four of the bimonthly conference calls highlighted particular topics (e.g., measuring impacts of local food projects) for discussion. Teams were also required to provide initial project logic models and quantitative and qualitative information on actual project outcomes.

The program had "top-down" elements of information transfer, with CEFS personnel and invited speakers giving instructional presentations. The PDP also had "bottom-up" elements, with teams brainstorming to define the goals, needs, and assets in their communities with regard to local foods, and defining the specific processes needed to bring a LFS project to fruition. The exact nature of the LFS project depended upon the context in which the networked community members were embedded. Under these circumstances, the importance of having a skilled Extension educator to lead and organize, acting as a convener of various constituencies who then generated a successful local foods project within one year, cannot be underestimated. Of the 12 projects, five focused on revitalizing existing or creating new farmers' markets; four projects provided support for existing or created new school or community gardens; one focused on creating a new farm tour; one created presentation materials to highlight the benefits of local food systems for various audiences; and one focused on working with existing community organizations to support local food events, including community meetings and meals.

As part of the final evaluation process, 11 of the 12 Extension team leaders were interviewed on their experiences during the project term. Interviews were semistructured and lasted from 30 minutes to one hour. One topic addressed during the interview prompted Extension educators to reflect on how the projects worked vis-à-vis community partners. This question was phrased to each 
interviewee as follows: "Did this particular project work any differently than others that you've been involved in, with regard to community partners?" Responses to this question illuminated the characteristics of LFS as a developing institutional field, and Extension educators' role in system change. Two major themes emerged from an analysis of the responses.

The first theme was that the PDP generated new communication and relationship networks around local foods. Extension agents noted that the collaboration brought together organizations having a general interest in "doing something" related to food, and functioned to inform all participants, including the agents themselves, of activities in the local community and in the state. As one agent explained:

Having the nontraditional partners (hospitals, restaurants, and tourism) was the biggest thing, and now those folks are really good partners, and they likely didn't have a clue as to what we (Extension agents) did before this project. This is an audience we don't usually reach, it is not part of our traditional audience.

The connections were structural and relational, bringing together a variety of entities and building concrete organizational and personal linkages; they were also cultural, with a diverse array of community members willing to associate under the cultural frame of "local foods." By stitching together new and unusual alliances, Extension educators set the stage for stable, preferential relationships, interorganizational linkages, and feedback loops upon which localized food systems could be built (Gulati \& Gargiulo, 1999; Ramasawmey \& Fort, 2011; Sundkvist et al., 2005). As one Extension educator noted:

We've worked to get the community used to local foods. When the Art Council has its gala, or the Chamber has its Evening of Stars, we work with them to source local foods.

One agent alluded to the cultural framing of local food as a means to bridge organizational and interest divides:
The neat thing about this local food culture [is that] we are beginning to find out what other people are doing and to collaborate. We partnered with [a county tourism office initiative], which is part of the Chamber (of Commerce), and they helped us organize and had some funding to help restaurateurs and chefs come (on our farm tour).

The PDP also helped educators meet new small farmers in their counties with whom they had not come into contact previously. This supplied the opportunity for Extension educators to contribute to rural revitalization by connecting the new generation of young farmers and food entrepreneurs with others interested in local food systems. A county horticultural agent who led one of the county-based projects noted:

There were a lot of people out there that I didn't know about — lots of farmers. This was a way for me to get to know them. And we've had a lot of new people move here, so this is a way to connect everyone.

A second dominant theme that emerged from a review of the responses was that the project leveraged resources through a cooperative project that bridged diverse communities. Having a distinct project goal around which partners could coalesce, along with modest seed funding (USD1,000 per county), were seen as key factors in building support and leveraging resources. As two agents explained:

Being part of this project was helpful in initially drawing community partners into the discussion. We could say "We have been selected" and I think saying that and saying we have a bit of resource money helped bring people to the table.

We approached [a local sustainable food nonprofit] and they cost-shared the advertising (for the farmers' market). We also approached Farm Bureau, and between those two we paid for all the marketing. Then we spent our USD1000 (in project funds) on the [farmers' market] billboard and rack card.... 
The money was really pivotal, it was a main building block and everything really fell into place.

Extension educators reported that the PDP acted as a catalyst to ground ideas that had been "floating" among various community groups, and focus these efforts on a common project. As a result, potential community resources - time, expertise, and funds - were leveraged by Extension institutional entrepreneurs. The following statements are emblematic of Extension educator responses related to collaboration and idea generation:

The PDP was an incentive for us to begin thinking creatively about how to start the conversation - no real plans had been there, the ideas had just been floating around in people's heads. [The PDP] gave us an incentive to get some action started.

Participating in the (PDP) process was beneficial, making us aware of resources across the state and getting us to focus on local foods as a central part of our work here. And that has happened. It was on our radar screen, but having this as a project and being accountable for it makes it a higher priority....This project has helped us focus on local foods as a core program.

By virtue of their structural position in and deep knowledge of their communities, educators were able to recruit collaborators, leverage resources, and link initiatives to ongoing community practices. This is illustrated by the experience of one PDP Extension leader. The agent found multiple ways to bring local food system ideas and practices into ongoing collaborations. For example, by hosting a local foods meal and presentation on the benefits of local food systems, the agent brought the idea of localizing food systems to a community development group that had in the past advocated for public spaces and greenways. As a result, the group rallied around local foods, beginning with a community "Home Grown" event to showcase locally grown foods, and then applying for community development funds to build a produce aggregation center. The agent also brought local food issues into discussion of the county farmland protection plan, using this as a vehicle to support local food systems in lieu of his PDP team's original idea of creating a food policy council. The agent's justification for working through an existing initiative was pragmatic: "There are already so many committees in the world," he noted, and it is "easier to find momentum than to try and create your own." Demonstrating a strategic knowledge of local conditions, the agent explained: "Whatever groups you are talking to, you are on their turf, they see the value and it is an easy way to engage and to give them ownership." Knowing where to "find momentum" and where ideas are likely to take hold is a unique and valuable resource held by Extension educators.

Extension agents were able to successfully act as conveners for food system initiatives because of the legitimacy conferred by the PDP project and by other LFS support efforts in the state. As noted by PDP leaders, having funding and being designated as a local food leader could be leveraged into support among groups previously uninvolved in local food system advocacy, including tourism, the arts, and the small business community. Extension legitimacy with respect to food systems has also been enhanced by three actions at the state level that have increased the visibility of the issue within both the agricultural community and the extension profession: establishment of the legislated North Carolina Sustainable Local Food Advisory Council (SLFAC), chaired by the commissioner of the Department of Agriculture and Consumer Services with support from CEFS, the North Carolina Farm Bureau, and other traditional agriculture entities; the creation of a new role within Cooperative Extension, called local food coordinators, with a coordinator in each of the state's 100 counties as well as five regional local food coordinators; and, in 2012, designation of local foods as a flagship Cooperative Extension program for the state. The state SLFAC submits policy recommendations that both remove barriers to and actively support local food system efforts, and is structured to include nonvoting subcommittee members to ensure input from a large network of cross-sector, grassroots 
leaders. The local food coordinators legitimize local foods as an Extension issue and identify a specific contact person for communities, while the flagship program makes it more likely that educator work will be supported with needed resources (e.g., funding, training materials, educational opportunities, new support positions, credibility, political opportunity).

\section{Empowering Extension Educators for Institutional Change}

A localized food system seeks to embed the production, distribution, and consumption of foods in community relationships (Morgan, Marsden, \& Murdoch, 2006). Over the past decade, interest and advocacy related to food and agri-food systems has spread from academics and community leaders working on rural economics and food security to professionals in business development, tourism, health, planning, and many other areas. Various groups have found common ground for discussion using the cultural frame of "local food." Proponents of local food systems have sought to localize food for a variety of different reasons: to enhance rural and urban economies, promote sustainable farms and farming practices, and improve individual health. "Local food" has thus worked effectively as a bridging device (Benford \& Snow, 2000) to bring together various constituencies to effect institutional change in the existing agri-food system.

Transformation in food systems, from national and global to more local, critically depends on harnessing the momentum and resources of individuals and organizations to create collaborative initiatives. Institutional change occurs as potential relationships among advocates solidify into actual coalitions, with actors in the emerging institutional field developing mutual awareness and practices becoming accepted and taken for granted (Barley \& Tolbert, 1997; Greenwood, Suddaby, \& Hinings, 2002; Lawrence \& Phillips, 2004; Maguire et al., 2004).

Evidence from the North Carolina program indicates that Extension educators can play a crucial role in cultivating relationships that heighten mutual awareness and enhance the adoption of localized practices of food production and con- sumption. Their experiences illustrate the unique skill and resource set of Extension as it could be used to build LFS, and suggest supports needed by educators to leverage these skills and resources for institutional change. In this concluding section we recommend four ways in which Extension educators could be further empowered to act as institutional entrepreneurs. Although these suggestions are applied specifically to LFS as concept and issue, they could also be applied to other areas of community interest that require a systems approach, including health, education, and sustainable economic development.

The first is continued legitimization of local foods as an important issue, with resources to back this up. A critical resource noted by the PDP leaders was information on the benefits of and strategies for developing localized food systems, and a communications structure to share information with collaborators. During the project term educators and community members coalesced around a distinct project, sharing information and linking to informational resources through the work of the project's lead organization. They exchanged information through agent-to-agent mentorship, bimonthly conference calls among project participants across project counties, and a midproject discussion forum at a regional sustainable agriculture conference. As the two-year grant concluded, agents expressed the need to continue to have the opportunity to learn about food systems and to network among peers on these issues. North Carolina's designation of local foods as a flagship Extension program indicates a commitment of resources at the state level and provides a mechanism for Extension staff to work across program areas. At the national level, current efforts to develop an eXtension virtual community of practice based on local and regional food systems provide a means to institutionalize information exchange on the issue, and ties into the Cooperative Extension Service's eXtension program, with which agents are already familiar. ${ }^{4}$ Validation of

\footnotetext{
${ }^{4}$ eXtension is a national Internet-based Cooperative Extension educational network accessible to the general public. For information on the developing eXtension Community of Practice focused on "Community, Local and Regional Food
} 
agent work and support for informational exchanges, both virtual and face-to-face, empowers agents to take the lead in food systems change.

A second way to support institutional entrepreneurship is to incorporate local food system ideas and initiatives within the established and familiar organizational routines associated with the Extension Service advisory boards. State- and countylevel advisory boards are designed to inform extension staff of community needs. Inertia in populating these boards with new members, however, may account for the recognized mismatch that sometimes occurs between emerging citizen concerns and boards' continued emphasis on traditional programming areas (Robinson, Dubois, \& Bailey, 2005). It is likely that the mismatch occurs simply because boards are not regularly rejuvenated with community members who are outside of these traditional programs. One way around entrenched advisory boards is creation of county or regional food policy councils or advisory committees that focus specifically on LFS, with leadership from CES. Or, deliberate efforts could be made to communicate promising local food programming to existing advisory board members and to populate boards with members who support food system localization activities. Each of these possibilities for board rejuvenation requires the support of the county extension director. Therefore, special attention should be made to work with county extension directors to increase awareness of the benefits of LFS and the successful outcomes of these systems in their state, region, and nationally.

A third means to empower institutional entrepreneurship is to stimulate integrated programming across all four extension program areas to draw upon diverse resources. Although cross-program contact is encouraged in Cooperative Extension new agent training (see for example Safrit, 2011), organizational structures such as the programspecific advisory boards and program-defined reporting structures can segregate information by program area. To mitigate this silo effect, crossprogram advisory groups could be used to forge relationships and generate integrated programming.

systems," see http://collaborate.extension.org/wiki/ Local Food Systems - for Extension Educators
A final suggested means to support agents is to design new measures of success to evaluate the food systems work of extension entrepreneurs. The current focus on monthly and annual reporting of program impacts encourages short-term educational programs that are insufficient to create systemic change. Measured impacts are often based on the number of individuals served, where this number depends on the actual number of individuals attending a training or field day, pre- and postmeasures of information gained during the training, and adoption of specific technical practices. These measurements correspond to diffusion models of behavioral change. The challenge now is to design measurements that can show evidence of and track institutional changes in the food system over time. Shifting from a reliance on "comprehensive counts of inputs and outputs" to evaluating change by "look[ing] for patterns of emergence" (Meter, 2010 , p. 25) poses a challenge to advocates of food localization, but is one that can bear significant fruit because it empowers change agents situated in advantageous structural and relational positions.

Researchers and practitioners involved in food system assessments have perhaps the greatest potential to design measurements as part of their ongoing work to identify valid and reliable measures of food systems and food environments. Deriving suitable reporting and assessment strategies and measures remains a substantial challenge. For the moment, prioritizing integrated programming and collaborations, and permitting a longer time frame for outcome reporting, may enhance extension educators' involvement. Working over a period of two or three years with multiple partners to successfully open a community garden, an urban farm, a community kitchen for value-added products, or a new or rejuvenated farmers' market should be considered a highly successful outcome for agents. Recognition that regional projects, perhaps not located in the agent's home county, are valid outcomes is also vitally important. A produce aggregation center serving multiple counties or consolidation of several small struggling rural farmers' markets into a strategically located multicounty market, perhaps not in the agent's home county, should be measures of agent success. Establishing mechanisms to gather information on 
food systems is also a key role that could be taken on by extension. Creating databases that link local producers and local businesses, identifying local producers who could supply schools and hospitals, and establishing mechanisms to track changes in these purchases over time are vital data-gathering activities and should be considered legitimate uses of extension time and be a part of agent work plans.

\section{In Closing}

CEFS's PDP project sought to build on the impressive innovation already existing in North Carolina offices of Cooperative Extension, with agents who have always been engaged with "local food" through their work with local farmers. Much of the success of the project is attributable to the inspiration of local extension staff and their capacity and willingness to work with partners in their communities.

The Cooperative Extension Service in North Carolina and other states is primed to lead in the transition to more regional and local food systems. Supporting the capacity and expertise of countybased field agents to serve as institutional entrepreneurs can enable agents to respond to the growing public demand for local foods through partnerships and can maintain the Extension Service's relevance in a challenging budgetary climate. As this shift occurs, it will be important to fully engage university-based research and extension faculty. While this may require a shift in focus from traditional agriculture research topics, it also invites collaboration with faculty and practitioners who have not traditionally worked in agriculture, including planning, supply chain development, and epidemiology and other areas of public health. It also provides the opportunity for cross-program collaboration in the field and among extension research specialists to address the need for measures to evaluate the work of localizing food systems and to determine which LFS-building initiatives "work" - and why and how. This collaboration and engagement with, recognition of, and support for extension's work as change agents can bolster the development of a self-perpetuating cycle of institutional change in food systems.

\section{Acknowledgements}

The authors extend their thanks to the North Carolina Cooperative Extension Service educators who worked on this project and to those who continue to work with their communities to localize food systems, and to the six anonymous JAFSCD reviewers for their numerous insightful comments and helpful suggestions on the manuscript.

\section{References}

Arsneault, S. (2000). Welfare policy innovation and diffusion: Section 1115: Waivers and the federal system. State and Local Government Review, 32(1), 4960.

Barley, S. R., \& Tolbert, P. S. (1997). Institutionalization and structuration: Studying the links between action and institution. Organization Studies, 18(1), 93-117.

Benford, R. D., \& Snow, D. A. (2000). Framing processes and social movements: An overview and assessment. Annual Review of Sociology, 26, 611-639.

Bohlen, J. (1961). The adoption and diffusion of ideas in agriculture. In J. H. Copp (Ed.), Our changing rural society: Perspectives and trends (pp. 265-287). Ames, Iowa: Iowa State University Press.

Boone, E. J., Safrit, R. D., \& Jones, J. (2002). Developing programs in adult education: A conceptual programming model (2nd ed.). Long Grove, Illinois: Waveland Press.

Born, B., \& Purcell, M. (2006). Avoiding the local trap: Scale and food systems in planning research. Journal of Planning Education and Research, 26, 195-207.

Chaves, M. (1996). Ordaining women: The diffusion of an organizational innovation. American Journal of Sociology, 101, 840-874.

Colyvas, J. A., \& Powell, W. W. (2006). Roads to institutionalization: The remaking of boundaries between public and private science. Research in Organizational Behavior, 27, 305-353.

DiMaggio, P. J. (1988). Interest and agency in institutional theory. In L. Zucker (Ed.), Institutional patterns and culture (pp. 3-22). Cambridge, Massachusetts: Ballinger Publishing Company.

DiMaggio, P. J., \& Powell, W. W. (1983). The iron cage revisited: Institutional isomorphism and collective rationality in organizational fields. American Sociological Review, 48, 147-160. 
Dorado, S. (2005). Institutional entrepreneurship, partaking, and convening. Organization Studies, 26(3), 385-414.

Feenstra, G. W. (2002). Creating space for sustainable food systems. Agriculture and Human Values, 19, 99-106.

Fligstein, N. (1997). Social skill and institutional theory. American Behavioral Scientist, 40, 397-405.

Greenwood, R., Suddaby, R., \& Hinings, C. R. (2002). The role of professional associations in institutional change. Academy of Management Journal, 45, 58-80.

Gulati, R., \& Gargiulo, M. (1999). Where do interorganizational networks come from? American Journal of Sociology, 104(5), 1439-1493.

Huffman,W. E., \& Evenson, R. A. (2006). Science for agriculture: A long-term perspective (2nd ed.). Oxford, UK: Blackwell.

Koc, M., \& Dahlberg, K. A. (1999). The restructuring of food systems: Trends, research, and policy issues. Agriculture and Human Values, 16(2), 109-116.

Lawrence, T., \& Phillips, N. (2004). From Moby Dick to Free Willy: Macro-cultural discourse and institutional entrepreneurship in emerging institutional fields. Organization, 11(5), 689-711.

Lev, L., Brewer, L., \& Stephenson, G. (2008). Tools for rapid market assessments [Special Report 1088-E; Oregon Small Farms Technical Report No. 6]. Corvallis, Oregon: Oregon State University Extension Service.

Lounsbury, M., Ventresca, M., \& Hirsch, P. M. (2002). Social movements, field frames and industry emergence: A cultural-political perspective on U.S. recycling. Socio-Economic Review, 1, 71-104.

Maguire, S. (2007). Institutional entrepreneurship. S. R. Clegg \& J. R. Bailey (Eds.), International Encyclopedia of Organization Studies (pp. 675-679). Thousand Oaks, California: SAGE Publications.

Maguire, S., Hardy, C., \& Lawrence, T. B. (2004). Institutional entrepreneurship in emerging fields: HIV/AIDS treatment advocacy in Canada. Academy of Management Journal, 47(5), 657-679.

Meter, K. (2006). Evaluating farm and food systems in the U.S. In B. Williams \& I. Imam (Eds.), Systems concepts in evaluation: An expert anthology. [American Evaluation Association monograph]. Point Reyes, California: EdgePress of Inverness.

Meter, K. (2010). Letting food systems emerge: How do we measure progress in an emergent system? Journal of Agriculture, Food Systems, and Community

Development, 1(1), 23-26.

Morgan, K., Marsden, T., \& Murdoch, J. (2006). Worlds of food: Place, power, and provenance in the food chain. Oxford: Oxford University Press.

National Sustainable Agriculture Coalition. (2012a). Senate Approves Agriculture Spending Bill [Web log post]. Retrieved from http://sustainable agriculture.net/blog/senate-agric-spending-bill/

National Sustainable Agriculture Coalition. (2012b). Agriculture appropriations chart, fiscal year 2013.

Retrieved May 5, 2012, from http://sustainableagriculture.net/wp-content/ uploads/2012/04/NSAC-FY-2013-AgAppropriations-Chart-Including-SenateCommittee-Action.pdf

North, D. (1991). Institutions. The Journal of Economic Perspectives, 5(1), 97-112.

Raison, B. (2010). Educators or facilitators? Clarifying extension's role in the emerging local food systems movement. Journal of Extension, 48(3). Retrieved from

http://www.joe.org/joe/2010june/comm1.php

Ramasawmy, B., \& Fort, F. (2011, 15-16 September). Can innovation be institutionally-driven? The case of institutional entrepreneurs in the restructuration of the Mauritian vegetable supply chain. $\sigma^{\text {th }}$ Proceedings of the European Conference on Innovation and Entrepreneurship. Robert Gordon University, Aberdeen, Scotland.

Rao, H., Morrill, C., \& Zald, M. N. (2000). Power plays: How social movements and collective action create new organizational forms. In R. I. Sutton \& B.M. Staw (Eds.), Research in Organizational Behavior, Volume 22 (pp. 239-282). Greenwich, Connecticut: JAI Press.

Robinson, L., Dubois, M., \& Bailey, C. (2005). Countylevel extension programming: Continuity and change in the Alabama Cooperative Extension system. Journal of Extension, 43(1). Retrieved from http://www.joe.org/joe/2005february/rb3.php

Rogers, E. M. (1983). Diffusion of innovations. Detroit: The Free Press.

Rogers, E. M. (2005). Diffusion of innovations [4 $4^{\text {th }}$ edition]. Detroit: The Free Press

Ryan, B., \& Gross, N. C. (1943). The diffusion of hybrid seed corn in two Iowa communities. Rural Sociology, 8, 15-24. 
Safrit, R. D. (2011, August). Overview of program development. PowerPoint presentation at New Extension Faculty Orientation Training, Raleigh, North Carolina.

Seevers, B., Graham, D., \& Conklin, N. (2007). Education through Cooperative Extension (2nd ed.). Columbus, Ohio: Ohio University Press, Curriculum Materials Service.

Sewell, W. H. (1992). A theory of structure: Duality, agency and transformation. American Journal of Sociology, 98(1), 1-29.

Strang, D., \& Soule, S. S. (1998). Diffusion in organizations and social movements: From hybrid corn to poison pills. Annual Review of Sociology, 24, 265-290.

Sundkvist, A., Milestad, R., \& Jansson, A. M. (2005). On the importance of tightening feedback loops for sustainable development of food systems. Food Policy, 30, 224-239.
Sustainable Agriculture Research \& Education [SARE]. (2012). Professional Development Program Overview. Retrieved March 15, 2012, from http://www.sare.org/ProfessionalDevelopment/PDP-Overview

Thomson, J. S., Radhakrishna, R., \& Bagdonis, J. (2011). Extension educators' perceptions of the local food system. Journal of Extension, 49(4). Retrieved from http://www.joe.org/joe/2011august/rb4.php

Tolbert, P. S., \& Zucker, L. G. (1983). Institutional sources of change in the formal structure of organizations: The diffusion of civil service reform, 1880-1935. Administrative Science Quarterly, 28, 22-39.

Valente, T. W., \& Rogers, E. V. (1995). The origins and development of the diffusion of innovations paradigm as an example of scientific growth. Science Communications, 16(3), 242-273. 